\title{
Avaliação de inseticidas para o controle de Thrips tabaci (Lindeman, 1889) (Thysanoptera: Thripidae) em campo, na cultura da cebola
}

\author{
Leandro D. Geremias ${ }^{ \pm=}$, , Paulo Antônio de S. Gonçalves ${ }^{(}{ }^{(}$, Renata S. Resende
}

Estação Experimental de Ituporanga, Empresa de Pesquisa e Extensão Rural de Santa Catarina-Epagri.

麦=-Corresponding author: leandrogeremias@epagri.sc.gov.br

Edited by: Sandra Maria Morais Rodrigues

Received: September 03, 2019. Accepted: October 31, 2019. Published: December 11, 2019.

Evaluation of insecticides for the control of Thrips tabaci (Lindeman, 1889) (Thysanoptera: Thripidae) on onion field

Abstract. The efficacy of 14 different insecticides was tested for the control of onion thrips Thrips tabaci (Lindeman, 1889) on onion in Itajai Valley, SC during 2018. The insecticides were sprayed six times at intervals of about seven days, we evaluated the number of nymph of thrips per plant 48 hours after spray, visually rated for thrips damage at 96 DAT and total and commercial onion bulb production. Significant diferences were observed between various insecticides evaluated. The treatments formetanate hydrochloride, spinetoram and abamectin proved the best thrips control, less thrips damage and good total and commercial productivity. The insecticide profenofos + cypermethrin exhibited reduction of thrips nymph and better total and comercial production comparing control however not reduced thrips damages. The insecticides thiacloprid, thiamethoxam + lambda-cyhalotrin, and Imidacloprid reduced the thrips density but had similar results for thrips damages and onion bulb production comparing with control, excepting total productivity for the neonicotinoids thiacloprid and and Imidacloprid..

Keywords: Onion thrips, Chemical control, Allium cepa.

O tripes da cebola, Thrips tabaci (Lindeman, 1889) (Thysanoptera: Thripidae), é a mais importante praga da cebola (Allium cepa) no mundo (Diaz-Montano et al. 2011). Trata-se de uma praga polífaga, com mais de 100 espécies de plantas hospedeiras, no entanto a cebola é seu hospedeiro preferencial (Gill et al. 2015). A área de produção de cebola no Brasil é de cerca de 52 mil de hectares, sendo cerca de $40 \%$ localizados no estado de Santa Catarina, e a região do Alto Vale do Itajaí (AVI) concentra a maior área cultivada com cebola no Brasil (Instituto Brasileiro de Geografia e Estatística - IBGE 2017).

Na região (AVI) em Santa Catarina ocorrem diversos problemas fitossanitários na cultura da cebola, especialmente surtos populacionais de T. tabaci (Gonçalves 2018) e doenças foliares (Menezes Júnior et al. 2016). Estes problemas são fatores limitantes para a produtividade na região e aumentam os custos de produção.

Adultos e ninfas de tripes alimentam-se das folhas da cebola causando lesões que provocam a redução na capacidade fotossintética, antecipam a senescência das folhas e reduzem a produção de bulbos (Gonçalves 2018). Como danos indiretos T. tabaci facilita a ocorrência de doenças bacterianas (Grode et al. 2017) além de ser o principal vetor do Iris Yellow Spot Orthotospovirus (IYSV, família Tospoviridae) (Kritzman et al. 2001), detectado em Santa Catarina em 2017 (Araújo \& Resende 2018) e tem causado grandes reduções na produção de cebola no AVI.

Inseticidas químicos sintéticos foliares são a principal ferramenta de controle do tripes da cebola. O controle químico de tripes é muito difícil por ser uma espécie de pequeno tamanho, hábitos crípticos e rápido crescimento populacional (Lewis 1997). Como reação os cebolicultores aumentam o uso de inseticidas, podendo acarretar problemas de ressurgência de pragas, danos ao meio ambiente e à saúde de consumidores e agricultores. Outro importante aspecto é a capacidade de algumas populações de $T$. tabaci desenvolverem resistência a inseticidas, fato muito comum em diversos países (Shelton et al. 2003, Herron et al. 2008).
Atualmente, existem 46 inseticidas comerciais pertencentes a seis grupos químicos (organofosforados, carbamatos, piretróides, neonicotinóides, espinosinas e análogo de pirazol) registrados para o controle de T. tabaci na cultura da cebola no Brasil (AGROFIT 2019). Entretanto, no estado de Santa Catarina os agricultores utilizam principalmente: cipermetrina + profenofós, lambda-cialotrina + tiametoxan e lambda-cialotrina, todos estes inseticidas contém produtos da classe química dos piretróides (IRAC MoA $=3 \mathrm{~A}$ ) de forma isolada ou em mistura. Este cenário pode aumentar o risco de surgimento de populações resistentes rapidamente.

Inseticidas com outros princípios ativos como abamectin, ciantraniliprole, espinosade, espinetoram e espirotetramate pertencentes a outros grupos químicos tem mostrado boa capacidade de controle de T. tabaci (Aguilar et al. 2017, Asgahar et al. 2018, Moretti \& Nault 2019). No entanto, a eficiência dos inseticidas varia em diferentes locais devido a sua toxicidade inerente para o inseto, além dos aspectos envolvendo a resistência e a dependência dos agricultores de um único inseticida ou classe de inseticidas (Shelton et al. 2003). Alguns destes inseticidas são registrados no Brasil, mas não têm sido avaliados visando ao controle de T. tabaci em cebola. Portanto, o objetivo deste estudo foi avaliar inseticidas foliares para o controle de T. tabaci na cultura da cebola em Ituporanga, na região AVI, Santa Catarina.

O experimento foi conduzido na Epagri - Empresa de Pesquisa Agropecuária e Extensão Rural de Santa Catarina, Estação Experimental de Ituporanga, (latitude $27^{\circ}, 22^{\prime \prime} \mathrm{S}$ e longitude $49^{\circ}, 35^{\prime \prime} \mathrm{W}$ ), altitude de $475 \mathrm{~m}$ em cambissolo em Ituporanga, Santa Catarina. As mudas (cultivar Epagri 362 Crioula Alto Vale) foram transplantadas em 01 de agosto de 2018. As parcelas foram constituídas de cinco linhas com 3,00 $\mathrm{m}$ de comprimento, espaçadas $35 \mathrm{~cm}$ entre elas e $8 \mathrm{~cm}$ entre plantas, totalizando 1,75 m de largura. As parcelas foram separadas por $1 \mathrm{~m}$ de distância sem plantio. As duas linhas externas foram consideradas como bordadura e apenas $2,5 \mathrm{~m}$ na parte central das parcelas foram 
utilizadas como área útil.

O controle de doenças e plantas invasoras foram realizados utilizando fungicidas e herbicidas recomendados para a produção de cebola em Santa Catarina (Menezes Júnior et al. 2016). Estas pulverizações foram uniformemente distribuídas em toda área. Nenhum inseticida além dos avaliados foi aplicado.

O delineamento experimental foi de blocos casualizados com 14 tratamentos (Tab. 1) e quatro repetições. Nos inseticidas avaliados não foi adicionado nenhuma substância, exceto para (Dicarzol $\left.{ }^{\circledR}\right)$ no qual foi adicionado açúcar ( $1 \%$ do volume de calda) devido a recomendação de bula para este produto. As aplicações foram realizadas utilizando um pulverizador costal pressurizado $\mathrm{CO}_{2}$ e equipado com quatro pontas tipo leque (AD 110.015), cada ponta separada por $50 \mathrm{~cm}$. O pulverizador foi anteriormente calibrado para liberar $270 \mathrm{~L} / \mathrm{ha}$ a 2,1 bar (30 PSI). Os tratamentos foram aplicados em 09 de outubro (69 dias após o transplantio, DAT), 17 de outubro (77 DAT), 23 de outubro (83 DAT), 30 de outubro (90 DAT), 06 de novembro (97 DAT) e 14 de novembro (105 DAT), totalizando seis aplicações.

O número de ninfas de tripes por planta foi contado visualmente em seis plantas, de forma aleatória, aproximadamente 48 horas após cada aplicação. As parcelas foram visualmente avaliadas para os danos de tripes em 05 de novembro aos 96 DAT. Nessa avaliação foi utilizada uma escala visual de notas, com os valores 1, 3 e 9, para níveis de danos, baixo, médio e alto de $T$. tabaci, respectivamente (Gonçalves et al. 2014).

A colheita dos bulbos ocorreu quando a maturação das plantas foi superior ou igual a $90 \%$. Os bulbos foram colhidos, curados em campo por dois dias e por uma semana em galpão, em seguida, foram pesados obtendo a produtividade total e classificados de acordo com Menezes Júnior et al. (2016), obtendo a produtividade comercial.

Os dados obtidos foram verificados quanto a normalidade e homocedasticidade das variâncias utilizando os testes de Bartlett e Shapiro-Wilk $(P<0,05)$, respectivamente. Quando necessário foram submetidos ao teste de Box-Cox para utilizar a transformação ótima da variável. Os dados foram submetidos a análise de variância (ANOVA) e as médias comparadas pelo teste de Skott-Knott $(P<0,05)$. Os dados foram analisados usando o programa estatístico $\mathrm{R}$.

Os tratamentos diferiram no número de ninfas de Thrips tabaci em todas as avaliações realizadas (Tab. 2). Na primeira avaliação, aos 69 DAT, os tratamentos tiacloprido, espinetoram, cloridrato de formetanato, imidacloprido, profenofós + cipermetrina e abamectina se destacaram com redução da incidência de tripes em relação ao controle (sem tratamento), com média de 23 ninfas por planta (variando de 17 para 26 ninfas). Os demais inseticidas apresentaram densidade de ninfas semelhantes ao controle média de 34 ninfas por planta.

Na segunda avaliação aos 77 DAT nenhum dos tratamentos reduziu a incidência de tripes. A partir da terceira avaliação, cloridrato de formetanato foi o tratamento mais efetivo na redução de ninfas de tripes na cebola. Em seguida, se destacaram espinetoram e abamectina. A partir da quarta avaliação tiametoxan + lambda-cialotrina, imidacloprido e profenofós + cipermetrina também apresentaram redução no número de ninfas de $T$. tabaci.

Considerando a média de ninfas de T. tabaci para todo período experimental, cloridrato de formetanato foi o mais efetivo. Novamente, os inseticidas espinetoram, abamectina, profenofós + cipermetrina e, imidacloprido, também reduziram a infestação de $T$. tabaci assim como tiacloprido e tiametoxan + lambda-cialotrina em relação ao controle. Os demais tratamentos apresentaram infestação média de ninfas por planta semelhantes ao controle.

As notas de dano, produção total e comercial de bulbos de cebola diferiram entre os tratamentos aplicados (Tab. 3). Danos inferiores de T. tabaci foram observados nos tratamentos espinetoram, cloridrato de formetanato e abamectina. Os tratamentos com menores danos de tripes também proporcionaram maior produção total de bulbos de cebola, com média superior a 20 t/ha e não diferiram de tiacloprido, imidacloprido e profenofós + cipermetrina. Para a produção comercial foi verificado desempenho superior para espinetoram, cloridrato de formetanato, profenofós + cipermetrina e abamectina com aumento de produção de cerca de 5 t/ha de bulbo em relação ao controle.
Os inseticidas estudados diferiram no controle de T. tabaci em cebola. A cultivar Crioula Alto Vale pode apresentar boa tolerância ao ataque de ninfas de tripes por planta, desde que haja práticas de manejo de solo com plantas de cobertura e precipitação pluviométrica regular (Gonçalves 1998). Este resultado é corroborado na presente pesquisa pois apenas os tratamentos que mantiveram a infestação média próxima a 20 ninfas por planta não tiveram alteração na produtividade comercial (Tab. 3).

Dentre os inseticidas avaliados, os pertencentes ao grupo dos piretróides (3A) apresentaram, de maneira geral, baixa eficiência no controle de T. tabaci. Lambda-cialotrina vem sendo utilizado na região há muitos anos com muita intensidade, até meados de 1990 este inseticida apresentava excelente eficiência no controle de tripes na cebola (Gonçalves \& Guimarães 1995). Porém, é provável que o uso intensivo tenha selecionado populações resistentes de $T$. tabaci a este princípio ativo. Embora sejam necessários estudos específicos, a rápida evolução da resistência para este princípio ativo já foi demonstrada para esta praga na cultura da cebola nos EUA (Shelton et al. 2003).

Os melhores inseticidas cloridrato de formetanato, espinetoram, e abamectina também se destacaram em outros estudos, quando utilizados mesmo princípio ativo ou grupo químico (Asgahar et al. 2018, Moretti \& Nault 2019). Os bons resultados observados com os neonicotinóides tiacloprido e imidacloprido também foram verificados recentemente no México no controle de T. tabaci em cebola (Aguilar et al. 2017).

Esta pesquisa permite conhecer a eficiência de diferentes inseticidas pertencentes a vários grupos químicos no controle de $T$. tabaci. A escolha dos inseticidas mais eficientes possibilita o agricultor reduzir as perdas causadas por tripes. Além de demonstrar eficiência dos produtos pertencentes a diferentes grupos químicos, possibilitando a rotação de princípios ativos como método pró ativo de manejo da resistência de tripes a inseticidas.

\section{Contribuições dos Autores}

L.D.G., P.A.S.G. e R.S.R. contribuíram para o delineamento e implantação da pesquisa, análise dos resultados e preparo do manuscrito.

\section{Referências}

AGROFIT (2019). Sistemas de agrotóxicos fitossanitários. <http:// extranet.agricultura.gov.br/agrofit_cons/principal_agrofit_cons>. Access on: vi.2019.

Aguilar, C. C.; González, R. A.; Pérez, R. A.; Ramírez, R. S. G.; Carapia, R. V. E. (2017). Combate químico de Thrips tabaci (Thysanoptera: Thripidae) en el cultivo de cebolla en Morelos, México. Acta Zoológica Mexicana, 33(1): 39-44. doi: 10.21829/ azm.2017.3311011

Araújo, E. R.; Resende, RS. (2018). Novo Vírus da Cebola: Iris Yellow Spot Virus. Florianópolis: Epagri. 2 p.

Asgahar M.; Baig, M. M. Q.; Afzal M.; Faisal N. (2018). Evaluation of different insecticides for the management of onion thrips (Thrips tabaci Lindeman, 1889) (Thysanoptera, Thripidae) on onion (Allium cepa L.) crops (2018). Polish Journal of Entomology, 87: 165-176. doi: 10.2478/pjen-2018-0012

Diaz-Montano J.; Fuchs M.; Nault B. A.; Fail J.; Shelton A. M. (2011). Onion thrips (Thysanoptera: Thripidae): A global pest of increasing concern in onion. Journal of Economic Entomology, 104(1): 1-13. doi: $10.1603 /$ ec10269

Gill, H. K.; Garg, H.; Gill, A. K.; Gillett-Kaufman, J. L.; Nault, B. A. (2015). Onion thrips (Thysanoptera: Thripidae) biology, ecology, and management in onion production systems. Journal of Integrated Pest Management, 6(1): 1-6. doi: 10.1093/jipm/pmv006

Gonçalves P. A. S.; Guimarães D. R. (1995). Controle químico de Thrips tabaci na cultura da cebola. Horticultura Brasileira, 13(1): 28-31.

Gonçalves, P. A. S. (1998). Determinação de nível de dano econômico de tripes em cebola. Horticultura Brasileira, 16(2): 128-131.

Gonçalves, P. A. S. (2018). Cebola: manejo de tripes. Revista Cultivar Hortaliças e Frutas, 15(108): 5-7 
Gonçalves, P. A. S.; Boff, P.; Menezes Júnior, F. O. G. (2014). Efeito de altas diluições de calcário de conchas e Natrum muriaticum no manejo fitossanitário, na produtividade e na armazenagem de cebola em sistema orgânico. Agropecuária Catarinense, 27(3): 7882.

Grode A.; Chen S.; Walker E. D.; Szendrei, Z. (2017). Onion thrips (Thysanoptera: Thripidae) feeding promotes infection by Pantoea ananatis in onion. Journal of Economic Entomology, 110(6): 23012307. doi: $10.1093 /$ jee/tox 273

Herron G.; James T. M.; Rophail J.; Mo J. (2008). Australian population of onion thrips, Thrips tabaci Lindeman (Thysanoptera: Thripidae), are resistant to some insecticides used for their control. Australian Journal of Entomology, 47(4): 361-364. doi: 10.1111/j.14406055.2008.00669.x

IBGE (2017). Levantamento Sistemático da Produção Agrícola. https://www.ibge.gov.br/estatisticas/economicas/agricultura-epecuaria/9201-levantamento-sistematico-da-producao-agricola. html?=\&t=o-que-e. Access on: vi.2019.
Kritzman A.; Lampel M.; Raccah B.; Gera, A. (2001). Distribution and transmission of Iris yellow spot virus. Plant Disease, 85(8): 838-842. doi: 10.1094/PDIS.2001.85.8.838

Lewis, T. (1997). Thrips as Crop Pests. New York: CAB International.

Menezes Júnior, F. O.; Marcuzzo, L.; Kurtz, C.; Alves, D. P.; Sgrott, E. Z; Araújo, E. R.; Higashikawa, F. S.; Wamser, G. H.; Palladini, L. A.; Gonçalves, P. A. S.; Oliveira, V. R. (2016). Manual de Boas Práticas Agrícolas: guia para a sustentabilidade das lavouras de cebola do estado de Santa Catarina. Florianópolis: Empresa de Pesquisa e Extensão Rural de Santa Catarina - Epagri.

Moretti, E. A.; Nault, B. A. (2019). Onion thrips control in onion, 2017. Arthropod Management Tests, 2019. 44(1): 1-2. doi: 10.1093/amt/ tsz003

Shelton, A. M.; Nault, B. A.; Plate, J.; Zhao, J. Z. (2003). Regional and temporal variation in susceptibility to lambda-cyhalothrin in onion thrips, Thrips tabaci (Thysanoptera: Thripidae) in onion fields in New York. Journal of Economic Entomology, 96(6): 1843-1848. doi: 10.1093/jee/96.6.1843

Tabela 1. Inseticidas (tratamentos) avaliados para o controle de Thrips tabaci em cebola. Ingrediente ativo, nome comercial (fabricante), grupo químico e doses utilizadas. Ituporanga, SC, 2018.

\begin{tabular}{|c|c|c|c|c|}
\hline $\begin{array}{c}\text { Tratamentos: } \\
\text { princípios ativos }\end{array}$ & $\begin{array}{c}\text { Nome comercial } \\
\text { (Fabricante) }\end{array}$ & Grupo Químico & Classificação IRAC ${ }^{1}$ & Doses \\
\hline Ciantraniliprole & Benevia (FMC) & Diamidas & 28 & $500 \mathrm{~mL} / \mathrm{ha}$ \\
\hline Tiacloprido & Calypso (Bayer) & Neonicotinóides & $4 \mathrm{~A}$ & $160 \mathrm{~mL} / \mathrm{ha}$ \\
\hline Espinetoram & Delegate (Corteva) & Espinosinas & 5 & $200 \mathrm{~g} / \mathrm{ha}$ \\
\hline Cloridrato de formetanato & Dicarzol (Cross Link) & Carbamatos & $1 \mathrm{~A}$ & $1.000 \mathrm{~g} / \mathrm{ha}$ \\
\hline Acetamiprido + Etofenproxi & Eleitto (Ihara) & $\begin{array}{l}\text { Neonicotinóides + } \\
\text { Éter difenílico }\end{array}$ & $3 A+4 A$ & $400 \mathrm{~mL} / \mathrm{ha}$ \\
\hline $\begin{array}{l}\text { Tiametoxan + Lambda- } \\
\text { cialotrina }\end{array}$ & Engeo Pleno S (Syngenta) & Neonicotinóides + Piretróides & $3 A+4 A$ & $300 \mathrm{~mL} / \mathrm{ha}$ \\
\hline Lambda-cialotrina & Karate Zeon (Syngenta) & Piretróides & $3 A$ & $100 \mathrm{~mL} / \mathrm{ha}$ \\
\hline Zeta-cipermetrina & Mustang (FMC) & Piretróides & $3 \mathrm{~A}$ & $240 \mathrm{~mL} / \mathrm{ha}$ \\
\hline Espiromesifeno & Oberon (Bayer) & Cetoenol & 23 & $500 \mathrm{~mL} / \mathrm{ha}$ \\
\hline Clorfenapir & Pirate (Basf) & Análogo de pirazol & 13 & $750 \mathrm{~mL} / \mathrm{ha}$ \\
\hline Fenitrotion + Esfenvalerato & Pirephos (Ihara) & $\begin{array}{l}\text { Organofosforados } \\
\text { + Piretróides }\end{array}$ & $1 B+3 A$ & $700 \mathrm{~mL} / \mathrm{ha}$ \\
\hline Imidacloprido & Provado (Bayer) & Neonicotinóides & $4 \mathrm{~A}$ & $350 \mathrm{~mL} / \mathrm{ha}$ \\
\hline Profenofós + Cipermetrina & Polytrin (Syngenta) & $\begin{array}{l}\text { Organofosforados } \\
\text { + Piretróides }\end{array}$ & $1 B+3 A$ & $500 \mathrm{~mL} / \mathrm{ha}$ \\
\hline Abamectina & Vertimec (Syngenta) & Avermectina & 6 & $500 \mathrm{~mL} / \mathrm{ha}$ \\
\hline Controle (Sem tratamento) & - & - & - & - \\
\hline
\end{tabular}

Tabela 2. Média de ninfas de tripes (Thrips tabaci), em diferentes tratamentos, amostradas 48 horas após a pulverização dos tratamentos (inseticidas). Ituporanga, SC, 2018.

\begin{tabular}{|c|c|c|c|c|c|c|c|}
\hline \multirow{2}{*}{ Tratamentos } & \multicolumn{7}{|c|}{ Número médio de ninfas por planta $( \pm E P M)^{1}$} \\
\hline & $69 \mathrm{DAT}^{2}$ & 77 DAT & 83 DAT & 90 DAT & 97 DAT & 105 DAT & $\begin{array}{l}\text { Média do } \\
\text { Período }\end{array}$ \\
\hline Ciantraniliprole & $36,88 \pm 8,13 b$ & $31,00 \pm 3,74 b$ & $30,21 \pm 4,91 \mathrm{c}$ & $23,63 \pm 1,94 \mathrm{c}$ & $23,25 \pm 4,60 \mathrm{c}$ & $48,21 \pm 7,66 b$ & $32,19 \pm 2,69$ e \\
\hline Tiacloprido & $26,38 \pm 4,39$ a & $24,16 \pm 6,28$ a & $31,95 \pm 2,97 \mathrm{c}$ & $26,67 \pm 1,66 \mathrm{c}$ & $21,21 \pm 6,14 \mathrm{c}$ & $42,92 \pm 9,02 \mathrm{~b}$ & $28,88 \pm 2,51 \mathrm{~d}$ \\
\hline Espinetoram & $23,25 \pm 2,55$ a & $20,12 \pm 2,87$ a & $13,83 \pm 2,15 b$ & $18,29 \pm 2,13 b$ & $8,75 \pm 1,05 b$ & $23,29 \pm 2,67$ a & $17,92 \pm 1,37 b$ \\
\hline Cloridrato de formetanato & $17,08 \pm 2,43 a$ & $15,62 \pm 2,84 \mathrm{a}$ & $8,54 \pm 1,48 a$ & $12,50 \pm 2,80 \mathrm{a}$ & $10,37 \pm 2,14 \mathrm{a}$ & $16,92 \pm 2,22 \mathrm{a}$ & $13,51 \pm 1,09 \mathrm{a}$ \\
\hline Acetamiprido + Etofenproxi & $40,59 \pm 6,00 \mathrm{~b}$ & $35,37 \pm 3,35 b$ & $26,87 \pm 2,48 c$ & $22,81 \pm 1,67 \mathrm{c}$ & $24,69 \pm 3,19 c$ & $54,33 \pm 4,81 b$ & $34,11 \pm 2,68 \mathrm{e}$ \\
\hline Tiametoxan + Lambda-cialotrina & $30,92 \pm 2,04 b$ & $32,83 \pm 4,82 b$ & $25,04 \pm 2,13 c$ & $19,63 \pm 1,16 b$ & $19,26 \pm 3,37 b$ & $29,79 \pm 2,53$ a & $26,24 \pm 1,53 d$ \\
\hline Lambda-cialotrina & $36,33 \pm 2,94 b$ & $28,46 \pm 4,07 \mathrm{~b}$ & $27,75 \pm 2,89 \mathrm{c}$ & $28,79 \pm 3,43 c$ & $32,84 \pm 8,55 c$ & $53,62 \pm 5,39 b$ & $34,63 \pm 2,59 \mathrm{e}$ \\
\hline Zeta-cipermetrina & $34,54 \pm 3,28 b$ & $28,21 \pm 2,77 b$ & $28,92 \pm 1,94 \mathrm{c}$ & $30,71 \pm 3,29 c$ & $30,63 \pm 3,23 c$ & $61,92 \pm 8,24 b$ & $35,82 \pm 2,92 \mathrm{e}$ \\
\hline Espiromesifeno & $31,17 \pm 3,11 b$ & $27,08 \pm 2,24 b$ & $29,13 \pm 2,19 \mathrm{c}$ & $24,09 \pm 2,51 \mathrm{c}$ & $24,80 \pm 1,78 \mathrm{c}$ & $49,79 \pm 9,32 b$ & $31,01 \pm 2,42 \mathrm{e}$ \\
\hline Clorfenapir & $30,50 \pm 3,61 b$ & $30,62 \pm 4,60 \mathrm{~b}$ & $31,04 \pm 0,63 \mathrm{c}$ & $27,08 \pm 1,80 \mathrm{c}$ & $24,87 \pm 3,07 c$ & $56,57 \pm 4,28 b$ & $33,45 \pm 2,51 \mathrm{e}$ \\
\hline Fenitrotion + Esfenvalerato & $31,00 \pm 2,46 b$ & $33,92 \pm 2,96 b$ & $29,09 \pm 3,12 c$ & $30,96 \pm 3,16 c$ & $29,75 \pm 7,52 \mathrm{c}$ & $46,80 \pm 7,39 b$ & $33,59 \pm 2,19$ e \\
\hline Imidacloprido & $23,29 \pm 3,51 \mathrm{a}$ & $20,75 \pm 3,09$ a & $25,42 \pm 3,76 c$ & $20,38 \pm 3,38 b$ & $15,50 \pm 0,62 b$ & $43,96 \pm 5,68 b$ & $24,88 \pm 2,30 c$ \\
\hline Profenofós + Cipermetrina & $23,54 \pm 4,02 \mathrm{a}$ & $24,71 \pm 1,53$ a & $21,38 \pm 1,83 c$ & $18,12 \pm 0,77 b$ & $20,80 \pm 6,46 b$ & $29,11 \pm 3,41$ a & $22,94 \pm 1,47 \mathrm{c}$ \\
\hline Abamectina & $25,79 \pm 2,03 a$ & $20,54 \pm 3,46$ a & $16,58 \pm 1,52 b$ & $17,07 \pm 0,71 b$ & $17,13 \pm 2,33 b$ & $23,88 \pm 1,83$ a & $20,16 \pm 1,08 c$ \\
\hline Controle (Sem tratamento) & $33,46 \pm 2,20 b$ & $23,08 \pm 4,29$ a & $22,96 \pm 0,91 \mathrm{c}$ & $27,33 \pm 2,11 \mathrm{c}$ & $32,56 \pm 4,75 c$ & $44,54 \pm 4,71 b$ & $30,66 \pm 2,00 \mathrm{e}$ \\
\hline$F(P)$ & $4,13(<0,01)$ & $3,39(<0,01)$ & $11,82(<0,01)$ & $7,72(<0,01)$ & $18,60(<0,01)$ & $12,64(<0,01)$ & $17,45(<0,01)$ \\
\hline
\end{tabular}

Médias seguidas da mesma letra, nas colunas, não diferem estatisticamente entre si $(\mathrm{P}<0,05) ;{ }^{1} \mathrm{EPM}$ - Erro padrão da média; ${ }^{2} \mathrm{DAT}-$ Dias após o transplante 
Tabela 3. Notas de danos, produtividade total e comercial de bulbos de cebola para os diferentes tratamentos. Ituporanga, SC, 2018.

\begin{tabular}{|c|c|c|c|}
\hline Tratamentos & Notas de danos & $\begin{array}{c}\text { Produtividade total } \\
\left.\text { (Kg/ha) }^{( \pm E P M}\right)^{1}\end{array}$ & $\begin{array}{c}\text { Produtividade comercial } \\
(\mathrm{Kg} / \mathrm{ha})( \pm \mathrm{EPM})^{1}\end{array}$ \\
\hline Ciantraniliprole & $3,75 \pm 0,54 b$ & $18.933,33 \pm 366,31 b$ & $17.266,67 \pm 433,40 \mathrm{~b}$ \\
\hline Tiacloprido & $3,55 \pm 0,30 b$ & $20.923,81 \pm 577,66$ a & $19.723,81 \pm 712,25 \mathrm{~b}$ \\
\hline Espinetoram & $1,50 \pm 0,19 a$ & $23.876,19 \pm 401,16$ a & $23.142,86 \pm 451,85$ a \\
\hline Cloridrato de formetanato & $1,30 \pm 0,06 \mathrm{a}$ & $25.380,95 \pm 188,78$ a & $24.504,22 \pm 236,81 \mathrm{a}$ \\
\hline Acetamiprido + Etofenproxi & $4,35 \pm 0,72 b$ & $17.430,48 \pm 386,86 \mathrm{~b}$ & $15.666,67 \pm 437,15 \mathrm{~b}$ \\
\hline Tiametoxan + Lambda-cialotrina & $3,00 \pm 0,75 b$ & $19.942,86 \pm 585,05 \mathrm{~b}$ & $18.000,00 \pm 734,86 \mathrm{~b}$ \\
\hline Lambda-cialotrina & $4,20 \pm 0,27 b$ & $19.238,09 \pm 370,33 b$ & $17.857,52 \pm 423,88 \mathrm{~b}$ \\
\hline Zeta-cipermetrina & $3,60 \pm 0,66 \mathrm{~b}$ & $18.695,24 \pm 517,18 b$ & $16.752,38 \pm 583,44 \mathrm{~b}$ \\
\hline Espiromesifeno & $3,40 \pm 0,18 b$ & $18.685,71 \pm 377,80 \mathrm{~b}$ & $17.114,29 \pm 372,39$ b \\
\hline Clorfenapir & $3,80 \pm 0,55 b$ & $17.428,57 \pm 214,16$ b & $15.228,57 \pm 211,73 \mathrm{~b}$ \\
\hline Fenitrotion + Esfenvalerato & $4,10 \pm 0,39 b$ & $18.590,48 \pm 515,40 \mathrm{~b}$ & $16.952,38 \pm 528,49 \mathrm{~b}$ \\
\hline Imidacloprido & $2,30 \pm 0,13 b$ & $21.281,05 \pm 346,57$ a & $19.666,62 \pm 395,23 \mathrm{~b}$ \\
\hline Profenofós + Cipermetrina & $3,20 \pm 0,82 b$ & $22.961,90 \pm 235,01$ a & $22.038,10 \pm 277,39$ a \\
\hline Abamectina & $1,70 \pm 0,17 a$ & $22.295,24 \pm 441,49$ a & $21.638,10 \pm 448,73 \mathrm{a}$ \\
\hline Controle (Sem tratamento) & $3,65 \pm 0,48 b$ & $19.419,05 \pm 758,62$ b & $17.857,14 \pm 944,71$ b \\
\hline$F(P)$ & $7,67(<0,01)$ & $5,80(<0,01)$ & $8,92(<0,01)$ \\
\hline
\end{tabular}

Médias seguidas da mesma letra, nas colunas, não diferem estatisticamente entre si $(P<0,05) ;{ }^{1} E P M-$ Erro padrão da média 